\title{
MECHANISM OF BACTERICIDAL ACTIVITY OF SILVER NITRATE - A CONCENTRATION DEPENDENT BI- FUNCTIONAL MOLECULE
}

\section{Sureshbabu Ram Kumar Pandian ${ }^{1}$, Venkataraman Deepak ${ }^{1}$, Kalimuthu Kalishwaralal ${ }^{1}$, Pushpa Viswanathan ${ }^{2}$, Sangiliyandi Gurunathan $^{1 *}$}

${ }^{1}$ Department of Biotechnology, Division of Molecular and Cellular Biology, Kalasalingam Academy of Research and Education, Anand Nagar, Krishnankoil-626190, Tamilnadu, India; ${ }^{2}$ Department of Electron microscopy, Cancer Institute (Women India Association), Chennai - 600020, Tamilnadu, India.

Submitted: June 04, 2009; Returned to authors for corrections: September 08, 2009; Approved: February 18, 2010.

\begin{abstract}
Silver nitrate imparts different functions on bacteria depending upon its concentration. At lower concentration it induced synthesis of nanoparticles, whereas at higher concentrations it induced cell death. Bacillus licheniformis was used as model system. The MIC was $5 \mathrm{mM}$, and it induced catalase production, apoptotic body formation and DNA fragmentation.
\end{abstract}

Key words: Silver nitrate, Bacillus licheniformis, nanoparticle synthesis, apoptosis, DNA fragmentation.

Gram positive bacteria are an important cause of serious infections particularly form hospitals and are getting resistance to many antibiotics (16). For quite a long time, silver has been known to impart antimicrobial activity to bacteria. Prior to the introduction of the Sulphadiazine cream, dilute solutions of silver nitrate were used to treat infections in the $19^{\text {th }}$ century (10). Silver-based antimicrobials can be effective in the treatment of infections on account non-toxicity of active $\mathrm{Ag}^{+}$to human cells (4). Interestingly, silver nitrate imparts different functions to bacteria depending upon its concentration. At higher concentrations, it kills bacteria, whereas, at lower concentrations it induces them to synthesize silver nanoparticles where Bacillus licheniformis (MTCC1483) is used for analysis. The biosynthesis of silver nanoparticles, as stated in our previous report (7) occurred at a concentration of $1 \mathrm{~m} M$ of silver nitrate. This was visualized by Scanning Electron Microscopy and XRD. The size of the nanoparticles was $\sim 50 \mathrm{~nm}$. Moreover, during the synthesis of silver nanoparticles the bacteria remained alive, and resumed their growth when the silver is removed from their environment (7).
Also, the nanoparticles accumulated inside the cells during incubation (Fig. 1). But, when the concentration of $\mathrm{AgNO}_{3}$ was increased, it induced cell death in bacteria. To analyze the antimicrobial function of $\mathrm{AgNO}_{3}$, bacteria was treated with various concentrations of silver nitrate and incubated for 2 mins. Subsequently, $0.1 \mathrm{ml}$ of the mixture was spread on nutrient agar for the formation of colonies, where soluble components in agar neutralized the action of silver. The result showed that $\mathrm{MIC}$ of $\mathrm{AgNO}_{3}$ was $5 \mathrm{~m} M$ i.e. the organism viability was completely inhibited when the concentration of silver is $5 \mathrm{mM}$. Many mechanisms have been suggested to explain the mode of bactericidal action of silver ions previously. They are known to inhibit proteins by binding to their thiol groups and denaturing them $(9,12)$ and prevent replication of DNA by its condensation (12). One mechanism under consideration in this report is Programmed Cell Death (Apoptosis). Usually, Programmed Cell Death (PCD) is associated with eukaryotic multicellular organisms. Recently, PCD systems have been observed in bacteria also (3).

Therefore to elucidate the mechanism, primarily the 




Figure 1. Transmission electron microscopic image of section of bacteria treated with $1 \mathrm{~m} M \mathrm{AgNO}_{3}$ containing accumulated silver nanoparticles inside the cell (at 50,000x).

morphology of the $\mathrm{AgNO}_{3}$ treated cells was continuously monitored under phase contrast microscopy. On observation it is noted that $\mathrm{AgNO}_{3}$ treated bacterial cells started to shrink resulting in characteristic apoptotic body formation. Apoptotic bodies were produced when the cell wall is permeabilized by silver ions. This shows that $\mathrm{AgNO}_{3}$ may induce apoptosis in $B$. licheniformis at higher concentration of $5 \mathrm{mM}$. Apoptotic bodies are greatly shrunken compared with normal cells and they are completely absent in cell populations not treated with silver nitrate. Catalase is one of the known free radical scavengers that scavenges hydrogen peroxide (2) a known active free radical. To check whether $\mathrm{AgNO}_{3}$ induces the catalase, an assay was carried out according to the method described by Lui et al., 2006 (10). The production of catalase was maximum at the MIC and decreased thereafter. When Reactive Oxygen Species (ROS) levels increase the cells undergo apoptosis (8). According to Matsumura et al., 2003 (12), the mutated strain UM1 (katE katG), deficient in catalase, was found to be more sensitive to both silver zeolite and silver nitrate than its parent. The outbreak of oxidative stress in bacteria is attributed to heavy metals like cadmium ions (9).

Silver ions are known to particularly inhibit thiol groupcontaining enzymes, such as NADH dehydrogenase II in the respiratory system, which is implicated as a candidate for the site of production of reactive oxygen species in vivo (12). Therefore, inhibition of this enzyme results in an increase in the free radical production. The increase in catalase production in the presence of ROS could be explained by the necessity for cells to reduce the concentration of $\mathrm{H}_{2} \mathrm{O}_{2}$, which is the source of the free radicals. It is proposed that reactive oxygen species can induce apoptotic pathways in bacteria which could ultimately lead to their death. Moreover, at higher concentrations of substrate i.e. $\mathrm{H}_{2} \mathrm{O}_{2}$, catalase gets inactivated (22). This also prevents catalase from acting upon $\mathrm{H}_{2} \mathrm{O}_{2}$. Apoptosis is complete when DNA gets fragmented which is observed in most of the eukaryotes (6). The same phenomenon 
is also observed in B. licheniformis. The DNA was found to undergo fragmentation in silver nitrate-treated cells. The fragmentation could be visualized in agarose gel with ethidium bromide. During the treatment, DNA fragmentation could be visualized in those cells which have been treated with concentration of $5 \mathrm{~m} M$ of $\mathrm{AgNO}_{3}$ and above. Whereas, no fragmentation was observed in those cells, that was treated with lesser concentration of $\mathrm{AgNO}_{3}$ (Data not shown).

Induction of apoptosis can be confirmed by two factors, irregular reduction in size of cells and DNA fragmantation. The cells reduced in size are called shrunken cells or apoptotic bodies (14) and DNA fragmentation is the final step in apoptosis (1). Previously there are reports available for induction of apoptosis in microorganisms. In E. coli, cell death is induced by a toxin - antitoxin (mazE - mazF) mechanism. The mazF gene encodes a stable toxin, MazF, while mazE encodes a labile antitoxin, MazE, degraded in vivo by the ATPdependent ClpPA serine protease. When the antitoxin degrades the cells undergo death (3). More interesting features are observed in Xanthomonas sp. The bacteria undergo programmed cell death under starvation. A caspase-3-like enzyme activity and apoptotic bodies are implicated in this organism, but not DNA fragmentation (5). A similar phenomenon is observed also in Streptomyces $s p$, where both apoptosis and a necrosis-like activity are observed (15). But in Plasmodium falciparum, a human malarial parasite, DNA fragmentation is observed when it is treated with chloroquinone $(8,13)$. Moreover, antibiotics also induce apoptosis in bacteria and current research is focused on new apoptotis-inducing antibiotics (14). Therefore, silver ions from silver nitrate are capable of inducing apoptosis in bacteria.

Moreover, the possible mechanisms for silver nanoparticle synthesis and the bactericidal action of silver ions are shown in Fig.2. At lower concentrations of silver nitrate, respiratory nitrate reductase may be involved in the production of nanoparticles (7). But at higher concentrations silver nitrate inhibits the action of proteins by reacting with their thiol groups (5) and also binds with the DNA, thus arresting its replication (12). Our results show that catalase production increases up to MIC and decreases thereafter. Catalase is a known scavenger of ROS; however its protective action seems to be restricted to low concentrations of silver nitrate (below the MIC). Catalase may also be inhibited by high concentrations of its substrate, hydrogen peroxide. Therefore, silver nitrate may induce apoptosis in bacteria through many ways.

As many organisms are developing resistance to drugs like methycillin resistant Staphylococcus aureus, penicillin resistant Streptococcus pneumonia which are highly associated with infections at hospitals (11), other molecules with antimicrobial activity are under research. The molecule can be exploited completely if the mechanism of action is known. It can be concluded that formation of shrunken cells and DNA fragmentation are induced by high concentrations of silver nitrate in B. licheniformis. However, the complete mechanism behind cell death is not clear. But it can be concluded that apoptosis is the major effect of the bactericidal action of silver nitrate. 




Figure 2. Possible mechanisms of the duality in functions of silver nitrate in bacteria. $\mathbf{A}$ - The left side of the figure shows the possible mechanism of silver nanoparticle synthesis at lower concentration which may involve nitrate reductase enzyme. B - The right side of the figure shows the possible mechanism for the induction of apoptosis by silver nitrate which may involve inactivation of thiol group containing proteins (e. g. NADH dehydrogenase II) and direct binding of silver to DNA thus stopping replication that certainly leading to apoptosis. 


\section{ACKNOWLEDGEMENTS}

The authors gratefully acknowledge the Tamilnadu State Council for Science and Technology (TNSCST), Council of Scientific and Industrial Research (CSIR) (Grant No: 37(1384)/09/EMR-II) and Dr H. Nellaiah for critically reading of the manuscript.

\section{REFERENCES}

1. Bortner, C.D.; Cidlowski, J.A. (2002). Apoptotic volume decrease and the incredible shrinking cell. Cell. Death. Differ., 9, 1307 - 1310.

2. Cabiscol, E.; Tamarit, J.; Ros, J. (2000). Oxidative stress in bacteria and protein damage by reactive oxygen species. Internatl. Microbiol., 3, 3-8.

3. Engelberg-Kulka, H.; Amitai, S.; Kolodkin-Gal, I.; Hazan, R. (2006). Bacterial Programmed Cell Death and Multicellular Behavior in Bacteria. PLOS. Genetics., 10, 135.

4. Ewald, A.; Susanne, K.; Thull, R.G.; Gbureck, U. (2006). Antimicrobial titanium/silver PVD coatings on titanium. BioMed. Eng. OnLine., 5, 22.

5. Gautam, A.S.; Sharma, A. (2002). Involvement of caspase-3 like protein in rapid cell death of Xanthomonas. Mol. Microbiol., 44, 393-401.

6. Hua, Z.J.; Xu, M. (2000). DNA fragmentation in apoptosis. Cell Res., 10, 205-211.

7. Kalimuthu, K.; Sureshbabu, R.; Venkatraman, D.; Bilal, M.; Gurunathan, S. (2008). Biosynthesis of silver nanocrystals by Bacillus licheniformis. Colloids. Surf. B. Biointerfaces., 65,150-153.

8. Lewis, K. (2000). Programmed Death in Bacteria. Microbiol. Mol. Biol. Rev., 64, 503-514.
9. Liau, S.Y.; Read, D.C.; Pugh, W.J.; Furr, J.R.; Russell, A.D. (1997). Interaction of silver nitrate with readily identifiable groups: relationship to the antibacterial action of silver ions. Lett. Appl. Microbiol., 25, 279283.

10. Lui, S.L.; Vincent, K.M.P.; Lung, I.; Burd, A. (2006). Antimicrobial activities of silver dressings: an in vitro comparison Margaret Ip. $J$. Med. Microbiol., 55, 59-63.

11. Maeno, E.; Ishizaki, Y.; Kanaseki, T.; Hazama, A.; Okada, Y. (2000). Normotonic cell shrinkage because of disordered volume regulation is an early prerequisite to apoptosis. PNAS. Early. Edition., 1-6.

12. Matsumura, Y.; Yoshikata, K.; Kunisak, S.; Tsuchido, T. (2003). Mode of Bactericidal Action of Silver Zeolite and Its Comparison with That of Silver Nitrate. Appl. Environ. Microbiol., 69, 4278-4281.

13. Picot, S.; Burnod, J.; Bracchi, V.; Chumpitazi, B.F.; Ambroise, T.P. (1997). Apoptosis related to chloroquine sensitivity of the human malaria parasite. Plasmodium falciparum. Trans. R. Soc. Trop. Med. Hyg., 91, 590-591.

14. Sat, B.; Hazan, R.; Fisher, T.; Khaner, H.; Glaser, G.; Engelberg-Kulka, H. (2001). Programmed Cell Death in Escherichia coli: Some Antibiotics Can Trigger mazEF Lethality. J. Bacterial., 183, 2041-2045.

15. Shirkhanzadeh, M.; Azadegan, M.; Liu, G. Q. (1995). Bioactive delivery systems for the slow release of antibiotics: incorporation of $\mathrm{Ag}+$ ions into micro-porous hydroxyapatite coatings. Mater. Lett., 24, 7-12.

16. Tally, F.P.; DeBruin, M.F. (2000). Development of daptomycin for gram positive infections. J. Antimicrob. Chemother., 6, 523- 526.

17. Yoshpe-purer, Y.; Henis, Y. (1976). Factors Affecting Catalase Level and Sensitivity to Hydrogen Peroxide in Escherichia coli. Appl. Environ. Microbiol., 32, 4465- 4469. 